TITLE:

\title{
Identification and in silico prediction of metabolites of the model compound, tebufenozide by human CYP3A4 and CYP2C19.
}

\section{$\operatorname{AUTHOR}(S)$ :}

Shirotani, Naoki; Togawa, Moe; Ikushiro, Shinichi; Sakaki, Toshiyuki; Harada, Toshiyuki; Miyagawa, Hisashi; Matsui, Masayoshi; ... Nishioka, Kazuhiko; Hirai, Nobuhiro; Akamatsu, Miki

\section{CITATION:}

Shirotani, Naoki ... [et al]. Identification and in silico prediction of metabolites of the model compound, tebufenozide by human CYP3A4 and CYP2C19.. Bioorganic \& medicinal chemistry 2015, 23(20): 6594-6601

\section{ISSUE DATE:}

2015-10-15

URL:

http://hdl.handle.net/2433/203077

\section{RIGHT:}

(c) 2015. This manuscript version is made available under the CC-BY-NC-ND 4 . 0 license

http://creativecommons.org/licenses/by-nc-nd/4.0/; The full-text file will be made open to the public on 15 October 2017 in accordance with publisher's 'Terms and Conditions for Self-Archiving'.; This is not the published version. Please cite only the published version,; この論文は出版社版でありません。引用の際には出版社版をご確認ご利用ください。 


\section{Graphical Abstract}

Identification and In Silico Prediction of Metabolites of Leave this area blank for abstract info. the Model Compound, Tebufenozide by Human CYP3A4 and CYP2C19

Naoki Shirotani, Moe Togawa, Shinichi Ikushiro, Toshiyuki Sakaki, Toshiyuki Harada, Hisashi Miyagawa, Masayoshi Matsui, Hirohisa Nagahori, Kazuki Mikata, Kazuhiko Nishioka, Nobuhiro Hirai, Miki Akamatsu*

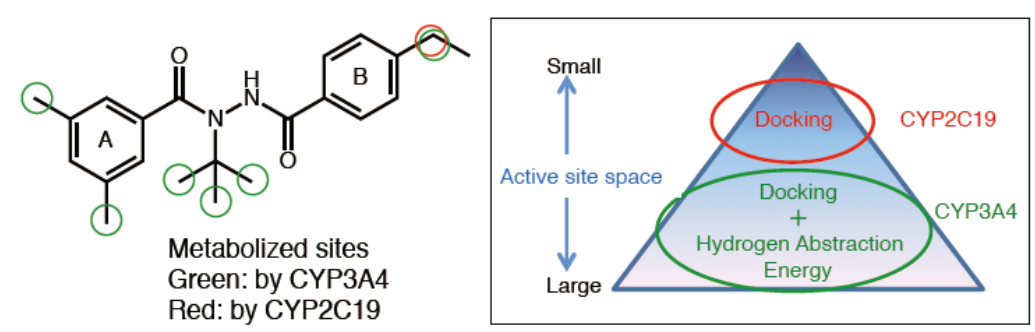


Identification and In Silico Prediction of Metabolites of the Model Compound, Tebufenozide by Human CYP3A4 and CYP2C19

Naoki Shirotani $^{\mathrm{a}}$, Moe Togawa ${ }^{\mathrm{a}}$, Shinichi Ikushiro ${ }^{\mathrm{b}}$, Toshiyuki Sakaki ${ }^{\mathrm{b}}$, Toshiyuki Harada ${ }^{\mathrm{a}}$, Hisashi Miyagawa $^{\mathrm{a}}$, Masayoshi Matsui ${ }^{\mathrm{c}}$, Hirohisa Nagahori ${ }^{\mathrm{c}}$, Kazuki Mikata ${ }^{\mathrm{c}}$, Kazuhiko Nishioka $^{\mathrm{c}}$, Nobuhiro Hirai $^{\text {a }}$, Miki Akamatsu ${ }^{\mathrm{a},}$ *

${ }^{a}$ Graduate School of Agriculture, Kyoto University, Kitashirakawa-oiwake-cho, Sakyo-ku, Kyoto 606-8502, Japan

${ }^{b}$ Faculty of Engineering, Toyama Prefectural University, 5180, Kurokawa, Imizu-shi, Toyama 939-0398, Japan

${ }^{a}$ Environmental Health Science Laboratory, Sumitomo Chemical Co., Ltd. 、1-98, Kasugade-naka 3-chome, Konohana-ku, Osaka 554-8558, Japan

*To whom correspondence should be addressed. (e-mail: akamatsu@kais.kyoto-u.ac.jp)

Corresponding Author:

Miki Akamatsu

Laboratory of Comparative Agricultural and Science

Graduate School of Agriculture

Kyoto University

Kyoto, Japan

Tel\&Fax: +81-75-753-6489

E-mail: akamatsu@kais.kyoto-u.ac.jp

Abbreviations: CYP, cytochrome P450; HLM, human liver microsome; RLM, rat liver microsome; DFT, density functional theory; NADPH, $\beta$-nicotinamide adenine dinucleotide phosphate reduced tetrasodium salt; $t_{R}$, retention time 


\begin{abstract}
:
The metabolites of tebufenozide, a model compound, formed by the yeast-expressed human CYP3A4 and CYP2C19 were identified to clarify the substrate recognition mechanism of the human cytochrome P450 (CYP) isozymes. We then determined whether tebufenozide metabolites may be predicted in silico. Hydrogen abstraction energies were calculated with the density functional theory method B3LYP/6-31G*. A docking simulation was performed using FRED software. Several alkyl sites of tebufenozide were hydroxylated by CYP3A4 whereas only one site was modified by CYP2C19. The accessibility of each site of tebufenozide to the reaction center of CYP enzymes and the susceptibility of each hydrogen atom for metabolism by CYP enzymes were evaluated by a docking simulation and hydrogen abstraction energy estimation, respectively.
\end{abstract}

Keywords: CYP3A4; CYP2C19; tebufenozide metabolites; docking simulation; hydrogen abstraction energy; in silico prediction 


\section{Introduction}

Humans are exposed on a daily basis to many chemicals and agrochemicals as residues in food and water or through occupational use. Metabolism and efflux systems have been developed to detoxify the xenobiotics absorbed by the body. The major metabolic pathways are mediated by the cytochrome P450 (CYP) superfamily, and genetic polymorphisms have been identified among the CYP isozymes. Therefore, examining the metabolic reactions by each CYP isozyme is important to elucidate their substrate recognition mechanisms. The clarification of these mechanisms may be useful not only for risk assessments of chemicals for humans, but also the development of new drugs and agrochemicals.

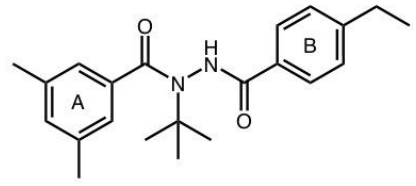

Fig.1 Structure of tebufenozide

In the present study, we identified the metabolites of the insecticide, tebufenozide, (Figure 1) formed by two human CYP isozymes: CYP3A4 and CYP2C19. CYP3A4 accounts for almost $50 \%$ of all CYP proteins in the human liver, and is the CYP isozyme involved in the metabolism of approximately $60 \%$ of commercially available drugs. ${ }^{1}$ Therefore, it is recognized as an isozyme that metabolizes substrates with diverse structures. ${ }^{1}$ CYP2C19 accounts for less than $1 \%$ of all CYP proteins, but it is known for genetic polymorphisms, for which approximately $20 \%$ of the Japanese population express the poor metabolizer phenotype. ${ }^{2}$ The substrate recognition mechanism of CYP2C19 needs to be elucidated in more detail because low CYP2C19 activity may lead to metabolic problems. Tebufenozide is an insect growth regulator that binds to ecdysone receptors, ${ }^{3}$ and is, thus, a safe insecticide for humans. However it has the asymmetrical hydrazine structure attached to two benzene rings with different substituents. Due to its unique asymmetrical structure, it was selected as a model compound for metabolism in this study. It is useful for elucidation of the substrate recognition mechanism to know how three different alkyl substituents, ethyl, dimethyl, $t$-butyl groups of tebufenozide are metabolized by different CYPs. Since one metabolite of tebufenozide, in which the ethyl- $\mathrm{CH}_{2}$ group of the B-ring is hydroxylated, is a chiral compound, we synthesized one enantiomer of the metabolite and determined the $R: S$ ratio of the metabolite by each CYP isozyme.

It was then determined whether the in silico prediction of the metabolites of tebufenozide was possible. We used the combined model of a docking simulation and hydrogen abstraction energy estimation for the metabolites of tebufenozide by CYP3A4 and CYP2C19. If there are several sites with sufficient accessibility in a compound, more susceptible sites will be metabolized, leading 
to the metabolite being hydroxylated at the site. CYP enzymes metabolize substrates in multiple steps, including hydrogen atom abstraction from a substrate by an activated oxygen intermediate in the enzyme active site. ${ }^{4,5}$ Since the rate-determining step for the hydroxylation reaction was attempted to be hydrogen atom abstraction, the abstraction energy of each hydrogen atom of a substrate may predict the susceptibility of metabolism by CYP enzymes. ${ }^{4,5}$ Olsen et al. reported a strong correlation between hydrogen abstraction energy and bond dissociation energy in transition-state models containing an activated oxygen intermediate and various substrates. ${ }^{4}$ Thus, the bond dissociation energy was calculated for the different types of hydrogen atoms of tebufenozide as a substitute for the hydrogen abstraction energy. A docking simulation was carried out to evaluate the accessibility of each hydrogen atom of tebufenozide to the reaction site of CYP3A4 and CYP2C19.

\section{Results}

\subsection{Identification of metabolites}

Tebufenozide was metabolized to three compounds M1, M3, and M4 (numbered according to the order of the HPLC retention time), by the recombinant yeast cells expressing human CYP3A4 and three compounds M1, M2, and M5 by CYP2C19. These metabolites were isolated and their structures, except for the M2 metabolite, were identified by their spectral data. The mass spectral data of M1, M3, and M4 indicated that they had the mono-hydroxylated tebufenozide structures. In comparison with the ${ }^{1} \mathrm{H}$ NMR spectrum of tebufenozide, the 4-ethyl- $\mathrm{CH}_{2}$ and $-\mathrm{CH}_{3}$ hydrogen atoms on the B-ring were shifted from $\delta 2.63(2 \mathrm{H})$ and 1.20 to $4.89(1 \mathrm{H})$ and $1.45 \mathrm{ppm}$, respectively, in M1. Furthermore, the broad peak of an $\mathrm{OH}$ hydrogen was appeared at $\delta 1.85 \mathrm{ppm}$ in M1. Thus, M1 was found to have a structure in which the 1-position of the ethyl group on the B-ring was hydroxylated. Since M1 has an asymmetric carbon atom at the hydroxylated site and, thus, it is a chiral compound, we synthesized racemic compound $( \pm)-\mathbf{1}$ and the $R$-enantiomer $(R-\mathbf{1})$ of M1 in order to determine the $R: S$ ratio of the metabolite by individual CYP isozymes. The $R$ : $S$ ratios of the metabolite by CYP3A4 and CYP2C19 were $33: 67$ and $2: 98$, respectively. In a similar manner, based on the chemical shift changes in the hydrogen atoms, one methyl group on the A-ring and of the $t$-butyl group were hydroxylated in M3 and M4, respectively.

The MS data and ${ }^{1} \mathrm{H}$ NMR spectrum of M5 showed the existence of a $\mathrm{CH}=\mathrm{CH}_{2}$ structure (molecular weight: $350, \delta 5.33,5.86$ and $6.73 \mathrm{ppm}$ ) instead of the ethyl group on the B-ring, suggesting the dehydration of M1 or dehydrogenation of tebufenozide catalyzed by CYP. ${ }^{6}$

Conversion of the ethyl group of tebufenozide to an acetyl group was suggested in M2, based on the MS data (molecular weight: 366) and ${ }^{1} \mathrm{H}$ NMR spectrum $[\delta 2.59 \mathrm{ppm}(3 \mathrm{H}, \mathrm{s})]$ of $\mathrm{M} 2$. 
However, it was difficult to elucidate the M2 structure due to the keto-enol tautomeric property of the compound. In some of the molecules, the acetyl group on the B-ring was considered to be converted to the enol form in the presence of acetic acid, which was used under the final HPLC purification condition. Thus, a compound with the putative M2 structure was synthesized. The HPLC and NMR data of the synthetic compound which was purified by recrystallization were consistent with the keto form of M2. Thus, the M2 structure was determined as $N$-(4-acetylbenzoyl)-N'-(3,5-dimethylbenzoyl)-N'-t-butylhydrazine (2).

The proposed MS fragmentation pathways for tebufenozide metabolites were shown in Figure 2, supporting the above metabolite structure identification.

The structures of the metabolites M1-M5 were shown with the production ratio of metabolites in Figure 3. The ethyl- $\mathrm{CH}_{2}$ group of the B-ring (M1), one methyl group of the A-ring (M3), and the $t$-butyl group (M4) were hydroxylated in metabolites by CYP3A4. In contrast, only the ethyl- $\mathrm{CH}_{2}$ group of the B-ring was modified in three metabolites by CYP2C19. These results showed that the substrate-binding site of CYP3A4 was larger than that of CYP2C19. Thus, substrates may interact with CYP3A4 by various binding modes, but by limited modes with CYP2C19.

The enzyme kinetics of $\mathrm{M} 1$ were investigated. $K_{\mathrm{m}}$ and $V_{\max }$ were $6.8 \mu \mathrm{M}$ and 12.7 $\mathrm{mol} / \mathrm{min} / \mathrm{mol} \mathrm{P} 450$ for CYP3A4 and $1.7 \mu \mathrm{M}$ and $2.1 \mathrm{~mol} / \mathrm{min} / \mathrm{mol} \mathrm{P} 450$ for CYP2C19. The affinity of tebufenozide for CYP2C19 was 4-fold higher than that for CYP3A4 whereas the maximum rate by CYP2C19 was 6-fold lower than that by CYP3A4.

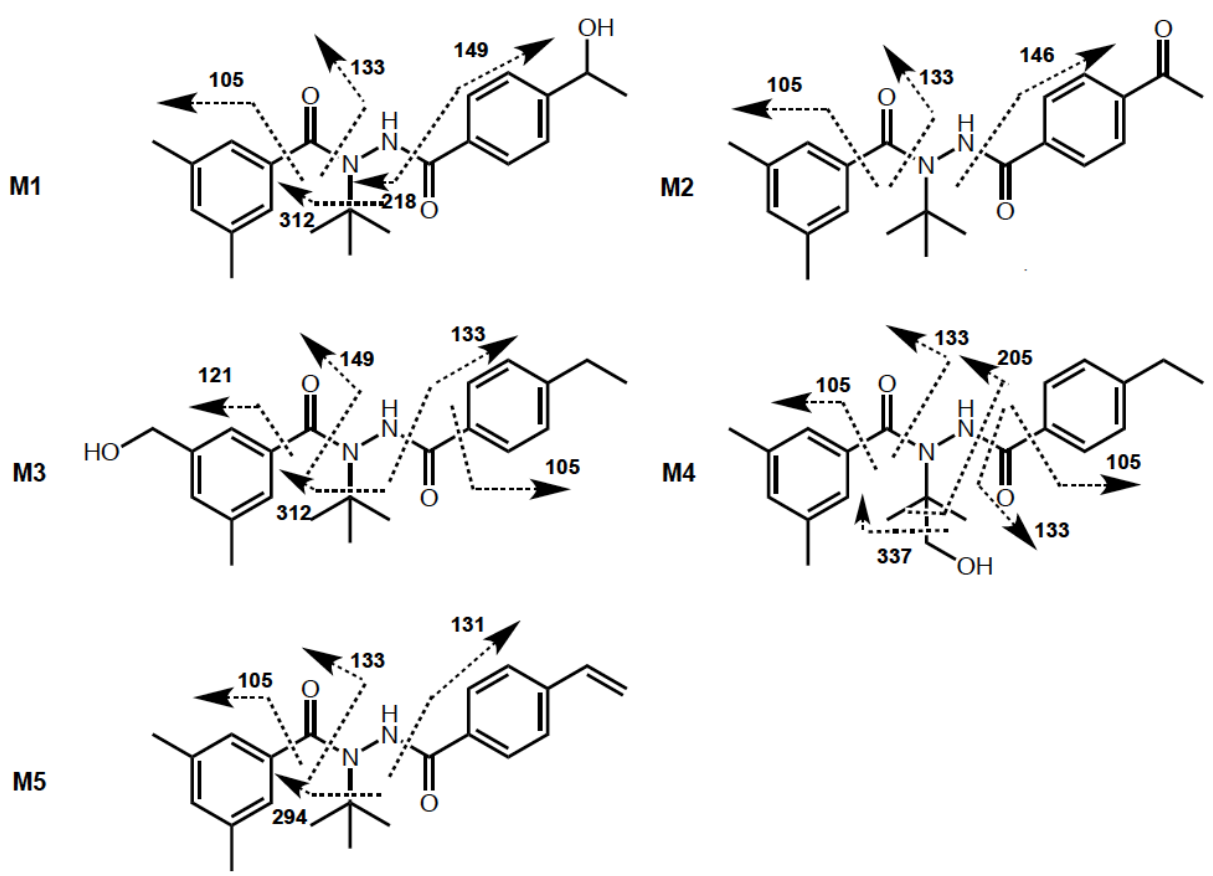

Fig. 2. Proposed MS fragmentation pathways for tebufenozide metabolites M1-M5 


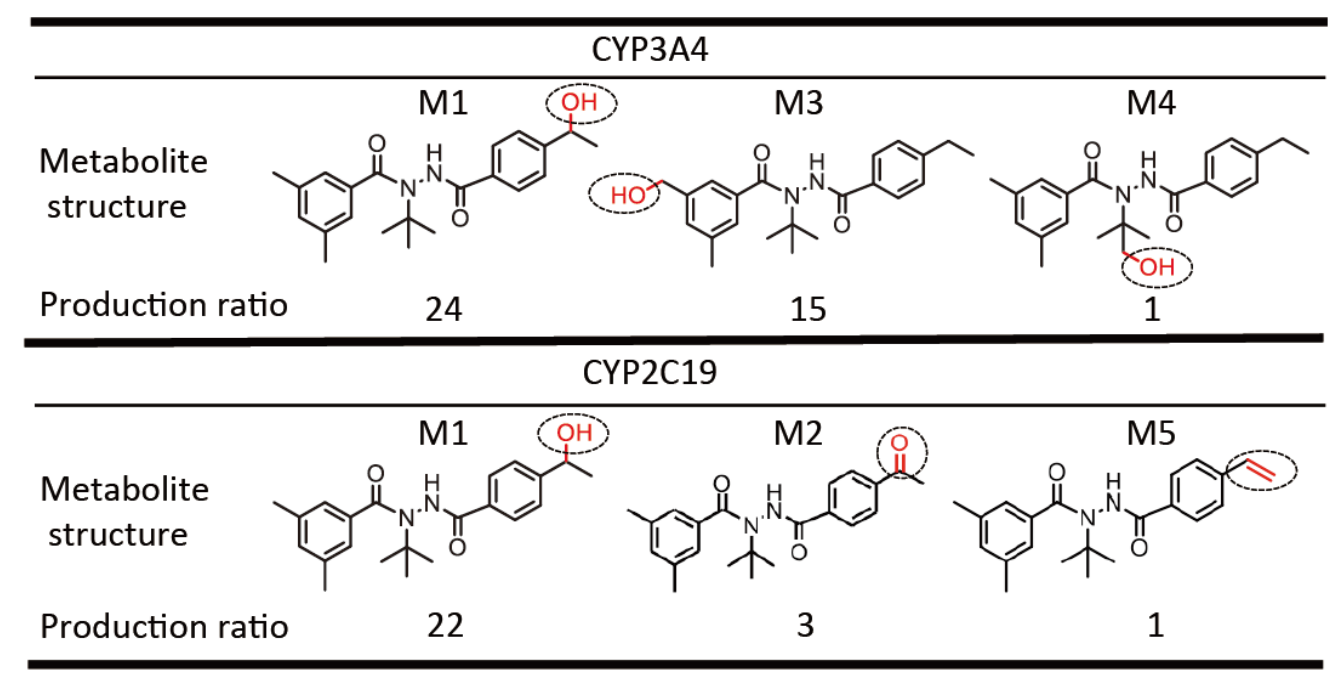

Fig. 3. Structures of tebufenozide metabolites with the production ratio by CYP3A4 and CYP2C19

\subsection{In silico prediction of metabolites}

The bond dissociation energy, $\Delta \mathrm{E}$, was calculated for the different types of hydrogen atoms of tebufenozide as a substitute for the hydrogen abstraction energy, as listed in Table 1. A smaller $\Delta \mathrm{E}$ value reflected the higher metabolism susceptibility of the group. Susceptibility was higher in the order of the ethyl- $\mathrm{CH}_{2}$ of the B-ring, $\mathrm{NH}$, methyl of the A-ring, ethyl- $\mathrm{CH}_{3}$ of the B-ring, $t$-butyl groups, and phenyl-H atoms.

Table 1. Bond dissociation energies of different types of hydrogen atoms of tebufenozide

\begin{tabular}{lr}
\hline Type of hydrogen & $\Delta \mathrm{E}(\mathrm{kcal} / \mathrm{mol})^{\mathrm{a}}$ \\
\hline A-ring Me & 87 \\
B-ring Ethyl- $\mathrm{CH}_{2}$ & 82 \\
B-ring Ethyl- $\mathrm{CH}_{3}$ & 99 \\
$t$-Butyl & 102 \\
phenyl-H & $109-110$ \\
$\mathrm{NH}$ & 84 \\
\hline${ }^{\mathrm{a}}$ The zero-point vibrational energy was \\
\multicolumn{2}{l}{ added. }
\end{tabular}

A docking simulation was carried out to evaluate the accessibility of each hydrogen atom of tebufenozide to the reaction site of CYP3A4 and CYP2C19. Many crystal structures are available for human CYP3A4. Two structures (PDBID: 3NXU, chain $\mathrm{A}^{7}$ and $3 \mathrm{UA} 1^{8}$ ), which are the 
complex with a ligand and have better resolutions ( $2 \AA$ and $2.15 \AA$, respectively), were used for docking. The crystal structure (PDBID: 4GQS, chain $\mathrm{A}^{9}$ ) was used for human CYP2C19. The 100 poses obtained after the constraint filtering for each CYP enzyme were visualized by VIDA, version 4.2.1 (OpenEye Scientific Software, Inc.; Santa Fe, New Mexico, USA). In these poses, the closest hydrogen atom to the oxygen atom attached to the heme-iron atom was considered to be abstracted and oxidized. The oxidation (hydroxylation) sites, frequency\% and the rank number of the highest ranked pose with the score (absolute value) for each site were shown in Table 2. 
Table 2. Oxidation sites, their frequency\%, and the rank number of the highest ranked pose (absolute value of score) of 100 poses by the docking simulation for each site

\begin{tabular}{|c|c|c|c|c|c|c|}
\hline \multirow[t]{3}{*}{ Oxidation Site } & \multicolumn{4}{|c|}{ CYP3A4 } & \multicolumn{2}{|c|}{ CYP2C19 } \\
\hline & \multicolumn{2}{|c|}{$3 \mathrm{UA} 1$} & \multicolumn{2}{|c|}{$3 \mathrm{NXU}$} & \multirow[b]{2}{*}{ frequency\% } & \multirow[b]{2}{*}{$\begin{array}{l}\text { rank number } \\
\left.\qquad \text { (score }^{\mathrm{a}}\right)\end{array}$} \\
\hline & frequency\% & $\begin{array}{c}\text { rank number } \\
\quad\left(\text { score }^{\mathrm{a}}\right)\end{array}$ & frequency $\%$ & $\begin{array}{c}\text { rank number } \\
\left(\text { score }^{\mathrm{a}}\right)\end{array}$ & & \\
\hline A-ring Methyl & 36 & $3(12.88)$ & 16 & $3(11.23)$ & 0 & - \\
\hline B-ring Ethyl- $\mathrm{CH}_{2}$ & 17 & $32(12.30)$ & 0 & - & 26 & $1(12.79)$ \\
\hline B-ring Ethyl- $\mathrm{CH}_{3}$ & 3 & 48 (11.98) & 0 & - & 74 & $4(12.23)$ \\
\hline$t$-Butyl & 42 & $1(13.13)$ & 61 & $1(11.54)$ & 0 & - \\
\hline Others $^{\mathrm{b}}$ & 2 & $62(11.76)$ & 23 & $7(10.72)$ & 0 & - \\
\hline
\end{tabular}

${ }^{a}$ Absolute value of the Chemgauss 4 score. The larger value, the better docking pose.

${ }^{\mathrm{b}}$ For 3UA1, A-ring 4-H (1), and B-ring 3-H (1); for 3NXU, A-ring 4-H (10), A-ring 2-H (6), B-ring 3-H (4), and B-ring 2-H (2). 
The oxidation site of the top pose for both structures of CYP3A4 (3UA1 and 3NXU) was the $t$-butyl group. The poses in which the $t$-butyl group was oxidized also appeared with the highest frequency. The second site was the methyl group of the A-ring. There were no poses in which the ethyl group of the B-ring was oxidized when the 3NXU structure was used for docking, whereas 17 and 3 poses in which the oxidation sites were the ethyl- $\mathrm{CH}_{2}$ and $-\mathrm{CH}_{3}$ group of the B-ring, respectively, were found using the 3UA1 structure. The NH group did not appear to be oxidized in the top 100 poses for both CYP3A4 structures. We also attempted to use the chain B of the $3 \mathrm{NXU}$ crystal structure, which has two chains A and B, for docking, and it was found that the result was similar to that using the chain A even if several residue positions are different in each chain (data not shown). In a comparison of the docking results, the docking using 3UA1, having a smaller volume of the active site shape predicted the oxidized sites of tebufenozide better than that using $3 \mathrm{NXU}$; however, it was difficult to predict the ratio of the experimentally obtained metabolites. Furthermore, the docking using 3UA1 gave the better score, for example, 13.13 and 11.54 for the best poses at the $t$-butyl group for $3 \mathrm{UA} 1$ and $3 \mathrm{NXU}$, respectively.

Regarding CYP2C19, the only poses in which the ethyl group of the B-ring $\left(\mathrm{CH}_{2}\right.$ or $\left.\mathrm{CH}_{3}\right)$ was oxidized were found at the frequency ratio $\left(\mathrm{CH}_{2}: \mathrm{CH}_{3}\right)=26: 74$. We also used the chain $\mathrm{C}$ of 4GQS for docking because the chains A and C of 4 chains of the 4GQS crystal structure have no missing portions. Although only 13 poses were obtained after the constraint filtering due to the smaller volume of the active site shapes than that of the chain A ( $388 \AA^{3}$ vs. $400 \AA^{3}$ ), the ethyl group of the B-ring in all poses except one pose (B-ring 3-H) was the closest moiety to the heme. The examples of the docking poses in which the ethyl- $\mathrm{CH}_{2}$ were closest to the heme are shown in Figure 4.
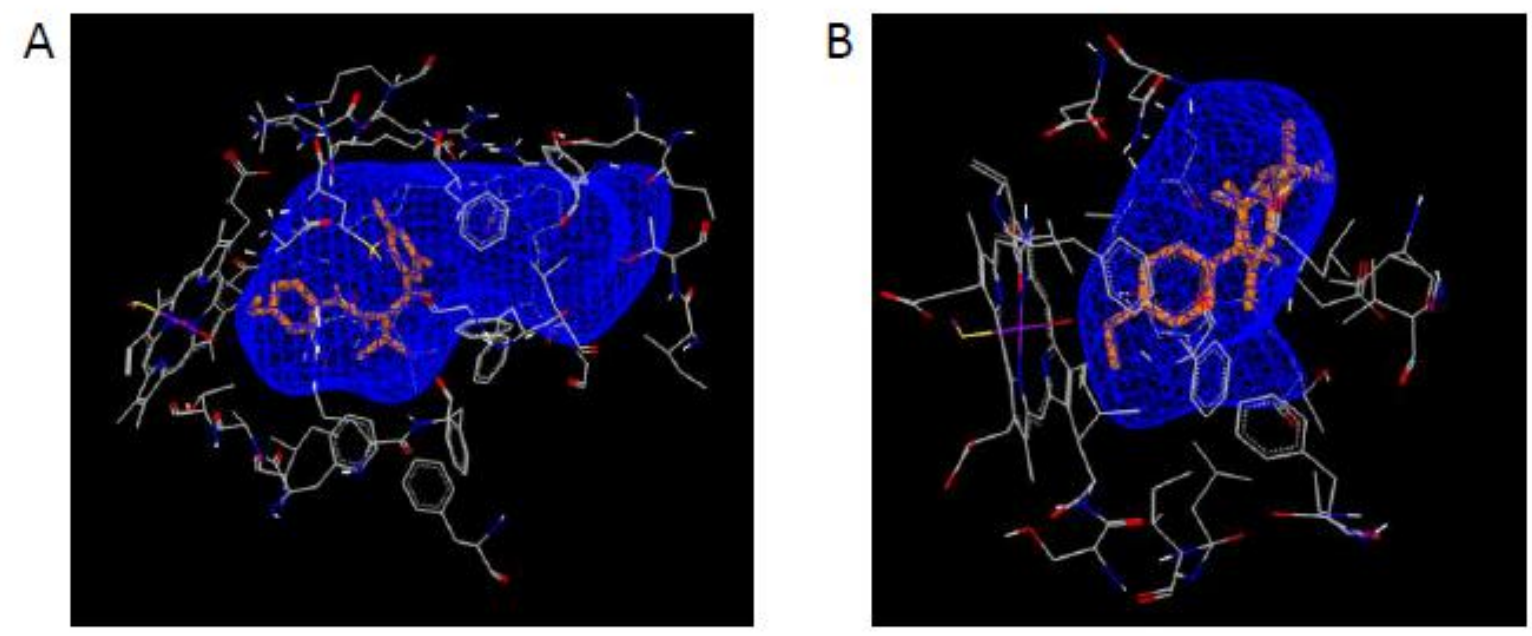

Fig. 4. Examples of docking poses of tebufenozide to CYP3A4 (PDB ID: 3UA1) (A) and CYP2C19 (B). Active site shapes and tebufenozide are shown by blue lines and the orange color, respectively. The heme is located at the left side of each figure. 


\section{Discussion}

\subsection{Metabolites of tebufenozide}

Metabolites of tebufenozide have been detected in rats. ${ }^{10}$ M1 (RH1788), M2 (RH6595), and M3 (RH9886) have been identified as rat metabolites and are also common in animals, plants and the environment. M5 (RH9841) has been found in crops. ${ }^{11}$ To date, only M4 in which the $t$-butyl group was hydroxylated has not been reported as a tebufenozide metabolite. We carried out a metabolic reaction of tebufenozide using human liver microsomes (HLM) and rat liver microsomes (RLM) and analyzed the metabolites by HPLC and LC/MS (data not shown). The metabolites, M1-M5 were detected in both reaction solutions after $1 \mathrm{hr} . \quad$ M4 and M5 were minor metabolites in humans and rats, and thus they have not been reported as animal metabolites. However, the production ratios of M1-M5 by HLM and RLM were almost identical, showing the similarity of both metabolism systems as already known.

\subsection{In silico prediction of metabolites}

The in silico prediction of metabolism by CYP enzymes has been performed from the point of view of toxicology and drug design. ${ }^{12}$ Prediction methodologies have been classified into four categories: [1] substrate orientation-based predictions, [2] mechanism-based predictions, [3] empirical and knowledge-based predictions such as quantitative structure-activity relationship models and rule-based expert systems, and [4] combined models of [1]-[3]. ${ }^{12}$ For category [1], the spatial alignment of substrates for the active site of CYP enzymes is important for the metabolic reaction. There are many docking programs such as Glide, ${ }^{13}$ GOLD,${ }^{14}$ and OEDocking, ${ }^{15}$ which predict energetically favorable binding conformations of the ligand into the active site cavity. Mechanism-based prediction approaches (category [2]) focus on the rate-limiting step of the catalytic cycle by estimating the activation energies of hydrogen abstraction. Activation energies have been estimated by semiempirical molecular orbital methods such as AM1 ${ }^{16}$ and PM3 ${ }^{17}$ as well as the density functional theory (DFT) method in previous studies including the pioneering work of Korzekwa et al. ${ }^{4,5,18,19}$

As an example of the category [3], Sheridan et al. reported empirical regioselectivity models for a few CYP enzymes. ${ }^{20}$ They estimated the AM1 dehydrogenation energy with a quantitative structure-activity relationship model using descriptors related to the local chemical environment of the atoms such as topological substructure parameters and hydrophobic moments. One of the combined methods, the category [4], was reported by Rydberg et al., named as SMARTCyp. ${ }^{21}$ SMARTCyp uses a reactivity descriptor and an accessibility descriptor for the $2 \mathrm{D}$ structure of 
drug-like molecules. The reactivity descriptor is an estimation of the energy required for a CYP to react with this position, which is similar to the approach by Singh et al. ${ }^{5}$ The energy was calculated for fragments and matching of the fragments was performed for the 2D structure of a molecule. The accessibility descriptor is similar to that defined by Sheridan et $a .^{20}$ as described above. The combined approach of ligand-based pharmacophore modeling with structure-based protein modeling by Groot et $a .^{22}$ and the combined model of catalyticphore-based docking with activation energy estimation, MLite ${ }^{23}$ have also been reported. Recent versions of MetaSite ${ }^{24}$ which uses both simplified docking by molecular interaction fields and fragment-based reactivity evaluation is classified into the category [4]. We took the combined model of a docking simulation for the accessibility and hydrogen abstraction energy estimation for susceptibility to predict the metabolites of tebufenozide by CYP3A4 and CYP2C19.

Regarding docking into CYP2C19, the only poses in which the ethyl group of the B-ring $\left(\mathrm{CH}_{2}\right.$ or $\mathrm{CH}_{3}$ ) was oxidized were found in the top 100 poses by the Chemgauss 4 score. Since the space around the heme $\mathrm{Fe}=\mathrm{O}$ in $\mathrm{CYP} 2 \mathrm{C} 19$ is narrow, only the ethyl group was allowed and fit in the space. The 3,5-dimethylbenzene and $t$-butyl group are bulky and, thus, they may not be allowed in the binding cavity. Three metabolites, in which only the ethyl- $\mathrm{CH}_{2}$ group of the B-ring was modified, were experimentally obtained by the reaction with CYP2C19. Since the bond dissociation energy of ethyl- $\mathrm{CH}_{3}$ was higher than that of ethyl- $\mathrm{CH}_{2}(17 \mathrm{kcal} / \mathrm{mol}$ difference in Table 1), the oxidation sites were successfully predicted in silico.

Docking poses, in which the $t$-butyl, methyl of the A-ring, ethyl group of the B-ring $\left(\mathrm{CH}_{2}\right.$ or $\mathrm{CH}_{3}$ ), and others (the 4-H on the A-ring and the 3-H of the B-ring) were oxidized, were found for CYP3A4 using the 3UA1 protein structure. The $t$-butyl, methyl of the A-ring, and the ethyl- $\mathrm{CH}_{2}$ group of the B-ring were experimentally oxidized by CYP3A4. Phenyl hydrogen atoms were not considered to be oxidized based on the highest bond dissociation energy of the hydrogen atoms on the benzene rings. Although the ethyl- $\mathrm{CH}_{3}$ group may be metabolized by the docking simulation, the frequency for the site was lower (only 3 poses) than those of the other sites. In addition, the high hydrogen dissociation energy and high flexibility of ethyl- $\mathrm{CH}_{3}$ made the metabolic reaction at the site unfavorable. Docking using 3UA1 with a smaller volume of the active site shape predicted the oxidized sites of tebufenozide better than that using 3NXU as described previously. CYP3A4 metabolizes various compounds. The binding of larger ligands such as ketoconazole, ritonavir, and erythromycin has been shown to require significant conformational changes in CYP3A4, while the binding of smaller ligands, even progesterone, induced no or very little conformational changes in the protein. ${ }^{25}$ Since tebufenozide does not appear to be a large ligand, docking using 3UA1 may give a better result.

Although the oxidation sites were predicted by docking simulation using the 3UA1 protein 
structure, the production ratio of metabolites in Figure 3 was not explained by the frequency of the poses. However, the order of the susceptibility by the bond dissociation energy corresponded with the production ratio.

It was difficult to predict the $R: S$ ratios of M1 by CYP3A4 and CYP2C19 in silico; however, the greater production of the $S$-enantiomer was predicted by a docking simulation $(R: S=6: 11$ for CYP3A4 (3UA1), $9: 17$ for CYP2C19). It may be difficult to detect such a subtle difference in the substrate orientation by the present docking algorithm.

\section{Conclusions}

Human CYP3A4 and CYP2C19 metabolized tebufenozide to five compounds (M1-M5) hydroxylated at different positions. Regarding the in silico prediction of metabolites, the accessibility of each site of tebufenozide to the reaction center of CYP enzymes and the susceptibility of each hydrogen atom for metabolism by CYP enzymes were evaluated by a docking simulation and hydrogen abstraction energy estimation, respectively. The hydroxylated sites and the production order of the metabolism of tebufenozide by CYP2C19 were successfully predicted by the combination of these two procedures. In the case of the metabolism by CYP3A4, the combination of the dissociation energies and the docking against 3UA1 could reasonably explain the hydroxylated sites and the production order. Even if there is only one example using a model compound, the combined models which were used in this study are expected to be useful for metabolite prediction. This in silico prediction of metabolites will provide important insights in order to elucidate the substrate recognition mechanisms of CYPs. The development of the models is now in progress for various compounds.

\section{Material and methods}

\subsection{Chemicals}

The standard of tebufenozide and $\beta$-nicotinamide adenine dinucleotide phosphate reduced tetrasodium salt (NADPH) were purchased from Wako Pure Chemical Industries (Osaka, Japan) and Sigma-Aldrich Co. LLC (St. Louis, Missouri, USA), respectively. All other reagents were of analytical grade and purchased from Wako Pure Chemical Industries or Nacalai Tesque (Kyoto, Japan). Microsomes containing baculovirus-expressed human CYP3A4 or CYP2C19 were purchased from Japan Corning Inc. (Tokyo, Japan).

Recombinant S. cerevisiae AH22 cells expressing human CYP3A4 or CYP2C19 with the vector pGYR were used to produce the metabolites of tebufenozide (4). ${ }^{26}$ The vector pGYR is an episomal S. cerevisiae/E. coli shuttle vector that contains $S$. cerevisiae NADPH-P450 reductase gene and a glyceraldehydes-3-phosphate dehydrogenase promoter as well as a terminator derived 
from zygosaccharomyces rouxii. ${ }^{26}$

\subsection{Metabolism of tebufenozide by CYPs}

The reaction mixture contained $200 \mu \mathrm{M}$ tebufenozide with $1 \%$ of acetonitrile and microsomes containing $67 \mathrm{nM}$ human CYP3A4 or CYP2C19 in $100 \mathrm{mM}$ phosphate buffer, pH 7.4. After a 2 min preincubation at $37^{\circ} \mathrm{C}$, the reaction was initiated by the addition of $\mathrm{NADPH}$ at a final concentration of $1 \mathrm{mM}$ at $37^{\circ} \mathrm{C}$ (in total $300 \mu \mathrm{l}$ ). The reaction was terminated by the addition of $600 \mu \mathrm{l}$ of acetonitrile and vigorous shaking after various time intervals. After centrifugation of the reaction solution $(7,000 \mathrm{G}, 10 \mathrm{~min})$, the acetonitrile phase was analyzed by HPLC (Shimadzu LC-10) and LC/MS (Shimadzu LCMS-2020).

HPLC analysis conditions; column: TSKgel ODS-100V $3 \mu \mathrm{m}(4.6 \times 150 \mathrm{~mm})$, temperature: $40^{\circ} \mathrm{C}$, solvent: A: $0.1 \%$ acetic acid in water; B: $0.1 \%$ acetic acid in methanol, gradient: $\mathrm{B}: 65 \%(0$ $\min )-65 \%$ (5 $\mathrm{min})-80 \%$ (20 $\mathrm{min})-100 \%$ (21 $\mathrm{min})-100 \%$ (24 $\mathrm{min})$, flow rate: $0.7 \mathrm{ml} / \mathrm{min}$, detection: UV $240 \mathrm{~nm}$

LC/MS analysis condition; LC; column: TSKgel ODS-100V $3 \mu \mathrm{m}(2.0 \times 150 \mathrm{~mm})$, temperature: $40^{\circ} \mathrm{C}$, solvent: A: $0.1 \%$ acetic acid in water; B: $0.1 \%$ acetic acid in acetonitrile, gradient: $\mathrm{B}: 42 \%(0$ $\min )-42 \%$ (5 min)-63\% (25 $\mathrm{min}$ )-90\% (27 $\mathrm{min})-90 \%$ (29 $\mathrm{min})$, flow rate: $0.2 \mathrm{ml} / \mathrm{min}$, detection: UV $240 \mathrm{~nm}$; MS; ion source: ESI, polarity: positive ion mode, monitor ions: 100-500 m/z

\subsection{Isolation and identification of metabolites}

Recombinant yeast cells expressing human CYP3A4 or expressing CYP2C19 were cultivated in a synthetic minimal medium containing $8 \%$ glucose, $5.4 \%$ yeast nitrogen base with ammonium sulfate, and $160 \mu \mathrm{g} / \mathrm{ml}$ L-histidine. Tebufenozide in acetonitrile was added at a final concentration of $20 \mu \mathrm{M}$ ( $2 \%$ acetonitrile) to the yeast cell culture. The yeast cell culture was cultivated at $30^{\circ} \mathrm{C}$ for $24 \mathrm{hrs}$. After centrifugation of the yeast cell culture $(6,000 \mathrm{G}, 3 \mathrm{~min})$, the supernatant was partitioned with ethyl acetate. The organic layer was dried over anhydrous sodium sulfate, and concentrated in vacuo. The residual oil dissolved in a small amount of methanol was purified by silica gel (Wakogel C-200, $7 \mathrm{~g}$ ) column chromatography with a stepwise gradient of $n$-hexane-ethyl acetate. The fractions eluted with $50 \%$ ethyl acetate in $n$-hexane were further purified by ODS column chromatography (YMC ODS-AM 120-S50, $14.8 \mathrm{~g}$ ) with a stepwise gradient of $0.1 \%$ acetic acid in water- $0.1 \%$ acetic acid in methanol. The fraction eluted with $0.1 \%$ acetic acid in $60 \%$ methanol was concentrated, and injected into an HPLC column. The compounds eluted at the retention time $\left(t_{R}\right) 9.5 \mathrm{~min}$ and $12 \mathrm{~min}$ in the following HPLC condition were collected to give 
metabolites M1 and M2, respectively. The fraction eluted with $0.1 \%$ acetic acid in $70 \%$ methanol was concentrated, and injected into an HPLC column. The compounds eluted at $t_{R} 10.5$ min, 14.5 min, and 15 min in the HPLC conditions described below were collected to give metabolites M3, M4, and M5, respectively. M1 (2.4 mg), M3 (0.2 mg) and M4 (0.1 mg) were obtained from a 1.2 L yeast cell culture expressing CYP3A4, while M1 (5.9 mg), M2 (0.2 mg), and M5 (3.1 mg) were obtained from a $1.35 \mathrm{~L}$ yeast cell culture expressing CYP2C19. ${ }^{1} \mathrm{H}-\mathrm{NMR}$ spectra were measured with a Bruker Avance III 400 (400 MHz for $\left.{ }^{1} \mathrm{H}\right)$ instrument. Mass spectra were measured with a JEOL JMS-600H mass spectrometer, Shimadzu LCMS-2020, and/or Thermo Fisher Scientific EXACTIVE. UV spectra were recorded with a Shimadzu UV-2200AI spectrometer.

HPLC isolation conditions; column: YMC ODS-AQ AQ-311 $(6.0 \times 100 \mathrm{~mm})$, temperature: 40 , solvent: M1 and M2: 0.1\% acetic acid in 60\% methanol; M3, M4 and M5: 0.1\% acetic acid in 70\% methanol, flow rate: $1.0 \mathrm{ml} / \mathrm{min}$, detection: UV $240 \mathrm{~nm}$

Tebufenozide (measured for comparison, only spectrum is available in ref. 27)

${ }^{1} \mathrm{H}$ NMR $\left(\mathrm{CDCl}_{3}\right): \delta 7.56(1 \mathrm{H}, \mathrm{s}, \mathrm{NH}), 7.33$ and $7.30\left(\right.$ each $2 \mathrm{H}$, d, each $J=8 \mathrm{~Hz}, \mathrm{C}_{6} \mathbf{H}_{4}$ of the B-ring), $7.05(2 \mathrm{H}, \mathrm{s}, 2,6-\mathrm{H}$ of the A-ring), $6.92(1 \mathrm{H}, \mathrm{s}, 4-\mathrm{H}$ of the A-ring), $2.63(2 \mathrm{H}, \mathrm{q}, J=8 \mathrm{~Hz}$, Et-CH$), 2.22\left(6 \mathrm{H}, \mathrm{s}, 2 \mathbf{C H}_{3}\right.$ on the A-ring), $1.59\left(9 \mathrm{H}, \mathrm{s}, \mathrm{C}\left(\mathbf{C H}_{3}\right)_{3}\right), 1.20(3 \mathrm{H}, \mathrm{t}, J=8 \mathrm{~Hz}, \mathrm{Et}-\mathrm{CH})_{3}$

\section{M1 (compound 1)}

${ }^{1} \mathrm{H}$ NMR $\left(\mathrm{CDCl}_{3}\right): \delta 7.66(1 \mathrm{H}, \mathrm{s}, \mathrm{NH}), 7.33$ and $7.30\left(\right.$ each $2 \mathrm{H}$, d, each $J=8 \mathrm{~Hz}, \mathrm{C}_{6} \mathbf{H}_{4}$ of the B-ring), $7.05(2 \mathrm{H}, \mathrm{s}, 2,6-\mathrm{H}$ of the A-ring), $6.92(1 \mathrm{H}, \mathrm{s}, 4-\mathrm{H}$ of the A-ring), $4.89(1 \mathrm{H}, \mathrm{q}, J=8 \mathrm{~Hz}$, Et-CH), $2.23\left(6 \mathrm{H}, \mathrm{s}, 2 \mathrm{CH}_{3}\right.$ on the A-ring), $1.85(1 \mathrm{H}, \mathrm{br}, \mathrm{OH}), 1.59\left(9 \mathrm{H}, \mathrm{s}, \mathrm{C}\left(\mathrm{CH}_{3}\right)_{3}\right), 1.45(3 \mathrm{H}, \mathrm{d}, J$ $=8 \mathrm{~Hz}, \mathrm{Et}-\mathrm{CH}_{3}$ ). MS EI m/z (rel. int.): 105 (11), 133 (100), 149 (23), 218 (1), 312 (26), 368 [M] ${ }^{+}$ (1). HRMS EI $m / z[M]^{+}$: Calcd. for $\mathrm{C}_{22} \mathrm{H}_{28} \mathrm{~N}_{2} \mathrm{O}_{3}: 368.2100$, Found: 368.2066

M2 (compound 2)

${ }^{1} \mathrm{HNMR}\left(\mathrm{CDCl}_{3}\right): \delta 7.89$ and 7.37 (each $2 \mathrm{H}$, d, each $J=8 \mathrm{~Hz}, \mathrm{C}_{6} \mathbf{H}_{4}$ of the B-ring), $7.62(1 \mathrm{H}, \mathrm{s}$, NH), $7.00\left(2 \mathrm{H}, \mathrm{s}, 2,6-\mathrm{H}\right.$ of the A-ring), $6.94(1 \mathrm{H}, \mathrm{s}, 4-\mathrm{H}$ of the A-ring $), 2.59\left(3 \mathrm{H}, \mathrm{s}, \mathrm{COCH}_{3}\right), 2.24$ $\left(6 \mathrm{H}, \mathrm{s}, 2 \mathbf{C H}_{3}\right.$ on the A-ring), 1.60 (9H, s, $\left.\mathrm{C}\left(\mathrm{CH}_{3}\right)_{3}\right) . \quad$ MS EI $m / z$ (rel. int.): 105 (34), 133 (100), 146 (9), $389[\mathrm{M}+\mathrm{Na}]^{+}(9), 405[\mathrm{M}+\mathrm{K}]^{+}(10)$

\section{M3 (compound 3)}

${ }^{1} \mathrm{HNMR}\left(400 \mathrm{MHz} \mathrm{CDCl}_{3}\right): \delta 7.67(1 \mathrm{H}, \mathrm{s}, \mathrm{NH}), 7.29$ and 7.15 (each $2 \mathrm{H}$, d, each $J=8 \mathrm{~Hz}, \mathrm{C}_{6} \mathbf{H}_{4}$ of the B-ring), $7.10\left(1 \mathrm{H}, \mathrm{s}, 4-\mathrm{H}\right.$ of the A-ring), $4.59\left(2 \mathrm{H}, \mathrm{d}, J=4 \mathrm{~Hz}, \mathrm{CH}_{2} \mathrm{OH}\right), 2.63(2 \mathrm{H}, \mathrm{q}, J=8 \mathrm{~Hz}$, Et-CH $\left.\mathbf{H}_{2}\right), 7.15\left(2 \mathrm{H}, \mathrm{s}, 2,6-\mathrm{H}\right.$ of the A-ring), $2.28\left(3 \mathrm{H}, \mathrm{s}, \mathrm{CH}_{3}\right.$ on the A-ring), $1.59\left(9 \mathrm{H}, \mathrm{s}, \mathrm{C}\left(\mathrm{CH}_{3}\right)_{3}\right)$, 
$1.20\left(3 \mathrm{H}, \mathrm{t}, J=8 \mathrm{~Hz}, \mathrm{Et}-\mathrm{CH}_{3}\right) . \quad$ MS EI $m / z$ (rel. int.): 105 (4), 121 (3), 133 (70), 149 (100), 312 (39), $368[\mathrm{M}]^{+}(1) . \quad$ HRMS EI $m / z[\mathrm{M}]^{+}$: Calcd. for $\mathrm{C}_{22} \mathrm{H}_{28} \mathrm{~N}_{2} \mathrm{O}_{3}: 368.2100$, Found: 368.2100

M4 (compound 4)

${ }^{1} \mathrm{HNMR}\left(\mathrm{CD}_{3} \mathrm{OD}\right): \delta 7.33$ and 7.21 (each $2 \mathrm{H}$, d, each $J=8 \mathrm{~Hz}, \mathrm{C}_{6} \mathbf{H}_{4}$ of the B-ring), 7.07 (2H, s, 2,6-H of the A-ring), 6.99 (1H, s, 4-H of the A-ring), $4.08\left(1 \mathrm{H}, \mathrm{d}, J=12 \mathrm{~Hz}, \mathrm{CH}_{2} \mathrm{OH}\right), 3.83(1 \mathrm{H}, \mathrm{d}$, $\left.J=12 \mathrm{~Hz}, \mathrm{CH}_{2} \mathrm{OH}\right), 2.65\left(2 \mathrm{H}, \mathrm{q}, J=8 \mathrm{~Hz}, \mathrm{Et}-\mathrm{CH}_{2}\right), 2.25\left(6 \mathrm{H}, \mathrm{s}, 2 \mathrm{CH}_{3}\right.$ on the A-ring), 1.52 and 1.48 (each $3 \mathrm{H}, \mathrm{s}, \mathrm{C}\left(\mathbf{C H}_{3}\right)_{2}$ of $t$-butyl), $1.20\left(3 \mathrm{H}, \mathrm{t}, J=8 \mathrm{~Hz}, \mathrm{Et}-\mathrm{CH}_{\mathbf{3}}\right) . \quad$ MS EI $m / z$ (rel. int.): 105 (12), 133 (79), 205 (100), 337 (7), $368[\mathrm{M}]^{+}$(7). HRMS EI m/z [M] $]^{+}$: Calcd. for $\mathrm{C}_{22} \mathrm{H}_{28} \mathrm{~N}_{2} \mathrm{O}_{3}$ : 368.2100, Found: 368.2005

M5 (compound 5)

${ }^{1} \mathrm{HNMR}\left(\mathrm{CD}_{3} \mathrm{OD}\right): \delta 7.43$ and 7.36 (each $2 \mathrm{H}$, d, each $J=7 \mathrm{~Hz}, \mathrm{C}_{6} \mathbf{H}_{4}$ of the B-ring), 7.07 (2H, s, 2,6-H of the A-ring), $6.99\left(1 \mathrm{H}, \mathrm{s}, 4-\mathrm{H}\right.$ of the A-ring), $6.73\left(1 \mathrm{H}, \mathrm{q}, J=18 \mathrm{~Hz}, 11 \mathrm{~Hz}, \mathrm{CH}=\mathrm{CH}_{2}\right), 5.86$ $\left(1 \mathrm{H}, \mathrm{d}, J=18 \mathrm{~Hz}, \mathrm{CH}=\mathrm{CH}_{2}\right), 5.33\left(1 \mathrm{H}, \mathrm{d}, J=11 \mathrm{~Hz}, \mathrm{CH}=\mathrm{CH}_{2}\right), 2.25\left(6 \mathrm{H}, \mathrm{s}, 2 \mathrm{CH}_{3}\right.$ on the A-ring), 1.59 (9H, s, C(CH $\left.)_{3}\right) . \quad$ MS EI m/z (rel. int.): 105 (19), 131 (29), 133 (100), 149 (24), 294 (28), 350 $[\mathrm{M}]^{+}(2)$. HRMS EI $m / z[M]^{+}$: Calcd. for $\mathrm{C}_{22} \mathrm{H}_{26} \mathrm{~N}_{2} \mathrm{O}_{2}: 350.1994$, Found: 350.1960

\subsection{Synthesis of compounds ( \pm )-1, $R-1$ and 2}

The synthesis scheme of the compounds $( \pm)-\mathbf{1}, R-\mathbf{1}$ and $\mathbf{2}$ is shown in Figure 5. Compound $\mathbf{2}$ was reduced to $( \pm)-\mathbf{1}$ by $\mathrm{NaBH}_{4}$ and to the $R-\mathbf{1}$ by $(S)-(-)-2$-methyl-CBS-oxazaborolidine.
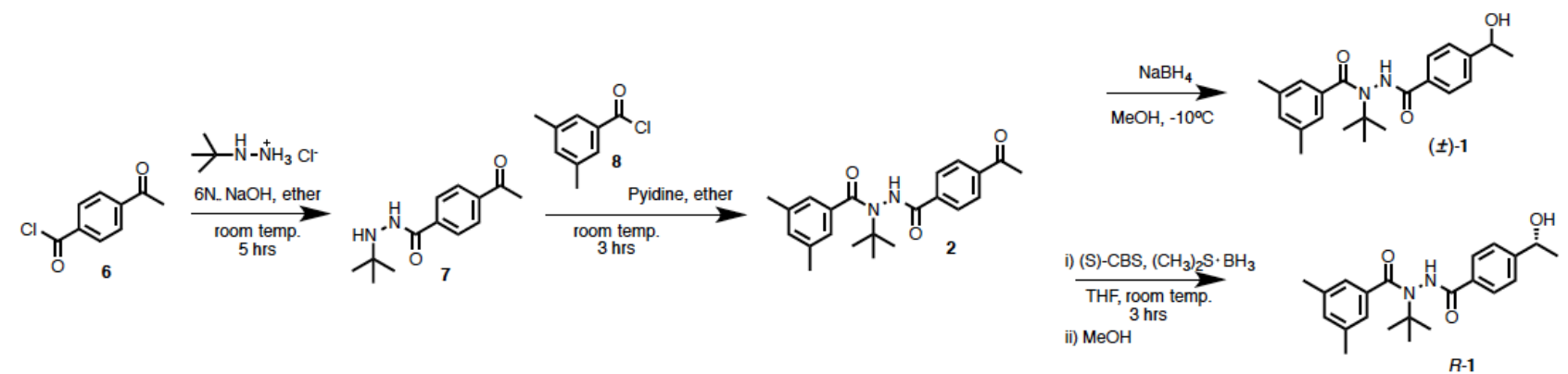

Fig. 5. The synthesis scheme of compounds with the M1 structure (racemic compound and $R$-enantiomer) and M2 structure

\subsubsection{Preparation of $N$-(4-acetylbenzoyl)- $N$ '-t-butylhydrazine (7)}

4-Acetylbenzoyl chloride (6) $(6.1 \mathrm{mmol})$ in $10 \mathrm{ml}$ ether and $6 \mathrm{~N} \mathrm{NaOH}(2 \mathrm{ml})$ were simultaneously added dropwise to $t$-butylhydrazine hydrochloride $(6.7 \mathrm{mmol})$ solution in $10 \mathrm{ml}$ ether. After stirring the mixture for $3 \mathrm{hrs}$ at room temperature, $100 \mathrm{ml}$ of saturated $\mathrm{NaCl}$ was 
added and the reaction product was extracted with ether $(50 \mathrm{ml} \times 3$ times). The ether layer was dried over anhydrous sodium sulfate. The solvent was removed under reduced pressure to give crude $N$-(4-acetylbenzoyl)- $N$ '- $t$-butylhydrazine (7) (yield 74\%). It was used to the next reaction without purification.

\subsubsection{Preparation of $N$-(4-acetylbenzoyl)- $N^{\prime}$-(3,5-dimethylbenzoyl)- $N$ '-t-butylhydrazine (2)}

Pyridine (1.49 mmol) was added to crude $N$-(4-acetylbenzoyl)- $N$ '-t-butylhydrazine (7) (1.49 mmol) solution in $1.5 \mathrm{ml}$ ether. 3,5-Dimethylbenzoyl chloride (8) (1.49 mmol) in $1.5 \mathrm{ml}$ ether was added dropwise to the reaction mixture. After the mixture was stirred for $3 \mathrm{hrs}$ at room temperature, it was purified by silica gel (Wakogel C-300, 20 g) column chromatography in a stepwise manner using mixed solvents: hexane/chloroform, hexane/ethyl acetate, and chloroform/methanol. The fraction eluted with chloroform : methanol $=6: 1$ was further purified by silica gel (Wakogel C-300, 6 g) column chromatography with chloroform : ethyl acetate = $10: 1$. The fraction eluted with $48 \mathrm{ml}$ of the solvent was concentrated, and the residue was recrystallized from a chloroform-hexane mixture to give colorless crystals (58 mg, yield $11 \%$ ). ${ }^{1} \mathrm{H}$ NMR $\left(\mathrm{CDCl}_{3}\right): \delta 7.90$ and 7.36 (each $2 \mathrm{H}, \mathrm{d}$, each $J=8 \mathrm{~Hz}, \mathrm{C}_{6} \mathbf{H}_{4}$ of the B-ring), $7.62(1 \mathrm{H}, \mathrm{s}, \mathrm{NH}), 7.00$ $\left(2 \mathrm{H}, \mathrm{s}, 2,6-\mathrm{H}\right.$ of the A-ring), $6.94(1 \mathrm{H}, \mathrm{s}, 4-\mathrm{H}$ of the A-ring $), 2.59\left(3 \mathrm{H}, \mathrm{s}, \mathrm{COCH}_{3}\right), 2.24(6 \mathrm{H}, \mathrm{s}$, $2 \mathrm{CH}_{3}$ on the A-ring), 1.60 (9H, s, $\left.\mathrm{C}\left(\mathrm{CH}_{3}\right)_{3}\right)$. MS ESI $m / z$ (rel. int.): 105 (33), 133 (100), 146 (3), $389[\mathrm{M}+\mathrm{Na}]^{+}(7), 405[\mathrm{M}+\mathrm{K}]^{+}(9)$. HRMS ESI m/z $[\mathrm{M}+\mathrm{H}]^{+}$: Calcd. for $\mathrm{C}_{22} \mathrm{H}_{29} \mathrm{~N}_{2} \mathrm{O}_{3}: 367.2016$, Found: 367.2008

\subsubsection{Preparation of racemic $N$-(4-(1-hydroxyethyl)benzoyl)- $N$ '-(3,5-dimethylbenzoyl)- $N^{\prime}$-t-butylhydrazine $[( \pm)-1]$}

Sodium borohydride

$(274$

nmol)

was

added

to $N$-(4-acetylbenzoyl)- $N$ '-(3,5-dimethylbenzoyl)- $N$ '-t-butylhydrazine (2) (137 nmol) solution in $5 \mathrm{ml}$ methanol. After stirring the mixture for $25 \mathrm{~min}$ at $-10^{\circ} \mathrm{C}, 10 \mathrm{ml}$ saturated $\mathrm{NaHCO}_{3}$ aq. solution and $20 \mathrm{ml}$ dichloromethane were added to the reaction mixture which was then stirred for $5 \mathrm{~min}$ at $0^{\circ} \mathrm{C}$. The dichloromethane layer was dried over anhydrous sodium sulfate. After the filtrated dichloromethane layer was concentrated, the residue was purified by silica gel (Wakogel C-300, 1.5 g) column chromatography with chloroform : ethyl acetate $=5: 1(12.3 \mathrm{mg}$, yield $24 \%) .{ }^{1} \mathrm{H}$ NMR $\left(\mathrm{CDCl}_{3}\right): \delta 7.99(1 \mathrm{H}, \mathrm{s}, \mathrm{NH}), 7.27$ and 7.26 (each $2 \mathrm{H}$, d, each $J=7 \mathrm{~Hz}, \mathrm{C}_{6} \mathbf{H}_{4}$ of the B-ring), 7.01 $(2 \mathrm{H}, \mathrm{s}, 2,6-\mathrm{H}$ of the A-ring), $6.91(1 \mathrm{H}, \mathrm{s}, 4-\mathrm{H}$ of the A-ring), $4.86(1 \mathrm{H}, \mathrm{q}, J=7 \mathrm{~Hz}, \mathrm{Et}-\mathrm{CH}), 2.21$ $\left(6 \mathrm{H}, \mathrm{s}, 2 \mathrm{CH}_{3}\right.$ on the A-ring), $2.15(1 \mathrm{H}, \mathrm{br}, \mathrm{OH}), 1.57\left(9 \mathrm{H}, \mathrm{s}, \mathrm{C}\left(\mathrm{CH}_{3}\right)_{3}\right), 1.43(3 \mathrm{H}, \mathrm{d}, J=7 \mathrm{~Hz}$, Et-CH$)_{3}$. MS ESI $m / z$ (rel. int.): 313 (72), $369[\mathrm{M}+1]^{+}(100)$. HRMS ESI $m / \mathrm{z}[\mathrm{M}+\mathrm{H}]^{+}$: Calcd. for $\mathrm{C}_{22} \mathrm{H}_{29} \mathrm{~N}_{2} \mathrm{O}_{3}: 369.2173$, Found: 369.2166 


\subsubsection{Preparation of $(R)-N-(4-(1-h y d r o x y e t h y l) b e n z o y l)-N '-(3,5-d i m e t h y l b e n z o y l)-$ $N^{\prime}$-t-butylhydrazine $(R-1)$}

(S)-(-)-2-Methyl-CBS-oxazaborolidine ((S)-CBS, $27 \mathrm{nmol})$ and borane dimethyl sulfide complex in $2 \mathrm{M}$ toluene $(0.27$ mmol $)$ were added to $N$-(4-acetylbenzoyl)- $N$ '-(3,5-dimethylbenzoyl)- $N$ '- $t$-butylhydrazine (2) (270 nmol) solution in $5 \mathrm{ml}$ tetrahydrofuran. After the mixture was stirred for $3 \mathrm{hr}$ at room temperature, $5 \mathrm{ml}$ methanol was added at $0^{\circ} \mathrm{C}$. The mixture was further stirred for $30 \mathrm{~min}$ at room temperature. After the solvent of the reaction mixture was evaporated, the residue was purified by silica gel (Wakogel C-300, $5 \mathrm{~g}$ ) column chromatography with chloroform : ethyl acetate $=4: 1$ and then $3: 1$ (85 mg, yield 85\%). ${ }^{1} \mathrm{H}$ NMR $\left(\mathrm{CDCl}_{3}\right): \delta 7.71(1 \mathrm{H}, \mathrm{s}, \mathrm{NH}), 7.32$ and 7.29 (each $2 \mathrm{H}$, d, each $J=8 \mathrm{~Hz}, \mathrm{C}_{6} \mathbf{H}_{4}$ of the B-ring), $7.04(2 \mathrm{H}, \mathrm{s}, 2,6-\mathrm{H}$ of the A-ring), $6.92(1 \mathrm{H}, \mathrm{s}, 4-\mathrm{H}$ of the A-ring), $4.89(1 \mathrm{H}, \mathrm{q}, J=7 \mathrm{~Hz}$, Et-CH), $2.23\left(6 \mathrm{H}, \mathrm{s}, 2 \mathrm{CH}_{3}\right.$ on the A-ring), $1.89(1 \mathrm{H}, \mathrm{br}, \mathrm{OH}), 1.59\left(9 \mathrm{H}, \mathrm{s}, \mathrm{C}\left(\mathrm{CH}_{3}\right)_{3}\right), 1.45(3 \mathrm{H}, \mathrm{d}, J$ $=7 \mathrm{~Hz}$, Et-CH$). \quad$ MS ESI $m / z$ (rel. int.): $313(81), 369[\mathrm{M}+1]^{+}(100) . \quad H R M S$ ESI $m / z[\mathrm{M}+\mathrm{H}]^{+}$: Calcd. for $\mathrm{C}_{22} \mathrm{H}_{29} \mathrm{~N}_{2} \mathrm{O}_{3}: 369.2173$, Found: 369.2167. $[\alpha]_{D^{17}}=+15.4^{\circ}(\mathrm{c} 5.4, \mathrm{MeOH})$

\subsubsection{Determination of the $R: S$ ratio of the M1 metabolite by each CYP}

The $R: S$ ratio of the M1 metabolites by each CYP was determined based on the HPLC retention time of the synthesized reference compounds. $R-\mathbf{1}$ and $( \pm)-\mathbf{1}$ were analyzed by HPLC using a chiral column. The $R: S$ ratio of the racemic compound was $1: 1$ as expected whereas that of $R$-enantiomer was $95: 5$, showing efficient chiral synthesis.

HPLC analysis condition; Column: CHIRALPAK AZ-H $3 \mu \mathrm{M}(4.6$ x $250 \mathrm{~mm})$; Temperature: $25^{\circ} \mathrm{C}$, Solvent: $90 \%$ hexane $/ 7 \%$ 2-propanol $/ 3 \%$ methanol, flow rate: $0.5 \mathrm{ml} / \mathrm{min}$; UV detection: $240 \mathrm{~nm}$

\subsubsection{Enzyme kinetics for $M 1$ production}

The reaction mixture contained $1-50 \mu \mathrm{M}$ tebufenozide with $2 \%$ of acetonitrile and the microsomes containing $67 \mathrm{nM}$ human CYP3A4 or CYP2C19 in $100 \mathrm{mM}$ phosphate buffer, pH 7.4. After a 2 min preincubation at $37^{\circ} \mathrm{C}$, the reaction was initiated by the addition of NADPH at a final concentration of $1 \mathrm{mM}$ at $37^{\circ} \mathrm{C}$ (in total $300 \mu \mathrm{l}$ ). After $5 \mathrm{~min}$ and $10 \mathrm{~min}$ for the reaction by CYP3A4 and CYP2C19, respectively, the reaction was terminated by the addition of $600 \mu$ of acetonitrile and vigorous shaking. After centrifugation of the reaction solution (7,000 G, $10 \mathrm{~min})$, the acetonitrile phase was analyzed by HPLC and the amount of M1 was calculated at each tebufenozide concentration. Based on the relationship between tebufenozide concentration and reaction rate $(\mathrm{mol} / \mathrm{min} / \mathrm{mol} \mathrm{P} 450), K_{\mathrm{m}}$ and $V_{\max }$ were calculated using Prism ver. 5.01 (Graphpad Software, Inc.; La Jolla, California, USA). 


\section{Calculation}

\subsection{Calculation of hydrogen abstraction energies}

The X-ray crystallographic structure of a derivative of tebufenozide (the compound having no substituents on benzene rings ${ }^{28}$ was modified to construct the structure of tebufenozide. The constructed structure of tebufenozide was energy-minimized by Tripos force fields using Sybyl ver. 7.3 (Sybyl Molecular Modeling Software; Tripos Associates, Inc.; St. Louis, Missouri, USA). The radical structures of tebufenozide were constructed by removing one hydrogen atom each from the energy-minimized tebufenozide structure. The energies of the radical and initial structures of tebufenozide, and a hydrogen atom were calculated with DFT method B3LYP (unrestricted formalism for open-shell systems) ${ }^{29-31}$ using Spartan version 10 (Wavefunction, Inc.; Irvine, California, USA). The 6-31G* basis set was used in the B3LYP calculations (unrestricted formalism for open-shell systems). To save the computational time, the bond dissociation energy, $\Delta \mathrm{E}$, which is the difference in energy between the substrate and the sum of the radical of the substrate and hydrogen atom, using optimized geometries for all three species, was simply calculated for each hydrogen atom as a substitute for the hydrogen abstraction energy by Eq. $1{ }^{4}$ The average energy was taken for equivalent hydrogen atoms such as 3 hydrogen atoms of a methyl group. The zero-point vibrational energy at the absolute zero temperature was added to the average energy.

$$
\Delta \mathrm{E}=\mathrm{E}(\text { radical of substrate })+\mathrm{E}(\mathrm{H})-\mathrm{E}(\text { substrate })
$$

\subsection{Docking simulation}

A docking simulation was carried out for in silico prediction of the metabolite structures using FRED software in OEDocking ${ }^{15}$, version 3.0.1 (OpenEye Scientific Software, Inc.; Santa Fe, New Mexico, USA). The multiconformer structure database of tebufenozide was generated by OMEGA, version 2.5.1 (OpenEye Scientific Software, Inc.; Santa Fe, New Mexico, USA) prior to docking. The same structure of tebufenozide as that used for the hydrogen abstraction energy calculation was used as an initial structure for OMEGA. Sixty conformers of tebufenozide were generated in the database.

Two crystal structures (PDBID: 3NXU, chain $\mathrm{A}^{7}$ and $3 \mathrm{UA}^{8}{ }^{8}$ ) of human CYP3A4 and the crystal structure (PDBID: 4GQS, chain $\mathrm{A}^{9}$ ) of human CYP2C19 were used for docking. Receptor files were generated using the structures of CYP3A4 and CYP2C19 by MAKE_RECEPTOR, one of applications in OEDocking version 3.0.1 (OpenEye Scientific Software, Inc.; Santa Fe, New Mexico, USA), after an oxygen atom was attached to the heme-iron atom using Sybyl ver. 7.3. The active 
site boxes were defined for CYP3A4 and CYP2C19 by the default setting of MAKE RECEPTOR. The boxes included all heavy atoms of the heme. The active site shape was described by a contour of the shape potential for each CYP enzyme and used for docking. The shape potential was created by docking multiple drug-like molecular probes, which were stored internally by the program, into the active site. The volumes of the active site shapes were $2,801 \AA^{3}, 1,202 \AA^{3}$ and $400 \AA^{3}$ for CYP3A4: 3NXU, 3UA1, and CYP2C19, respectively.

Each conformer in the multiconformer structure database of tebufenozide was attempted to dock into the active site shapes of CYP3A4 or CYP2C19 using FRED. Scoring functions, Chemgauss3 in the first exhaustive docking step and Chemgauss 4 in the second optimization step were used for FRED to evaluate the ligand-receptor affinity. The Chemgauss4 score is always a negative value. Thus, a pose with a larger absolute value of Chemgauss 4 score was defined as the higher ranked pose. The top 100 ranked poses in terms of the Chemgauss 4 score for each CYP enzyme were selected. A constraint condition was defined using a utility program, receptor_toolbox in OEDocking in order for every pose to have at least one heavy atom within $3.2 \AA$ [The sum of van der Waals radii of carbon $(1.7 \AA)$ and oxygen $(1.5 \AA)$ atoms] of the oxygen atom attached to the heme-iron atom. The top 100 ranked poses were filtered by the constraint condition.

\section{Acknowledgments}

We are grateful to OpenEye Scientific Software, Inc. and Daicel Corporation for using software, OMEGA, OEDocking, and VIDA, and helping with the HPLC analysis using a chiral column, respectively. We thank Ms. Karin Nishimura (Kyoto University) for the high resolution mass spectral measurements of several compounds. We also thank Dr. Yoshiaki Nakagawa (Kyoto University) for his helpful advice and comments, and Messrs. Masataka Yagawa and Hiroaki Edamatsu for their assistance with docking and energy calculations. This work was supported in part by a Grant in-Aid for Scientific Research (22510229) from the Ministry of Education, Culture, Sports, Science and Technology of Japan.

\section{References and notes}

1. Riley, R. J.; Parker, A. J.; Trigg, S.; Manners, C. N. Pharm. Res. 2001,18, 652-655.

2. Bertilsson, L. Clin. Pharmacokinet. 1995, 9, 192-209.

3. Billas, I. M. L.; Iwema, T.; Garnier, J.-M.; Mitschler, A.; Rochel, N.; Moras D. Nature 2003, 426, 91-96.

4. Olsen, L.; Rydberg, P.; Rod, T. H.; Ryde, U. J. Med. Chem. 2006, 49, 6489-6499.

5. Singh, S. B.; Shen, L. Q.; Walker, M. J.; Sheridan, R. P. J. Med. Chem. 2003, 46, 1330-1336.

6. Obach, R. S. $\quad$ Drug Metab. Dispos. 2001, 29, 1599-1607. 
7. Sevrioukova, I. F.; Poulos, T. L. Proc. Natl. Acad. Sci. USA 2010, 107, 18422-18427.

8. Sevrioukova, I. F.; Poulos, T. L. J. Biol. Chem. 2012, 287, 3510-3517.

9. Reynald, R.L.; Sansen, S.; Stout, C. D.; Johnson, E. F. J. Biol. Chem. 2012, 287, 44581-44591.

10. Grant, S.; Ma, S. JMPR : 921_Tebufenozide (Pesticide residues in food 1996 evaluations Part II Toxicological) (1996). URL (http://www.inchem.org/documents/jmpr/jmpmono/v96pr11.htm) (May 28, 2015).

11. Food and Agriculture Organization of the United Nations. Tebufenozide. URL (http://www.fao.org/ag/AGP/AGPP/Pesticid/JMPR/Download/2001_eva/ 15\%20Tebufenozide.pdf) (September 18, 2009).

12. Tarcsay, Á.; Keserü, G. M. Expert Opin. Drug Metab. Toxicol. 2011, 7, 299-312.

13. Friesner, R. A.; Banks, J. L.; Murphy, R. B.; Halgren, T. A.; Klicic, J. J.; Mainz, D. T.; Repasky, M. P.; Knoll, E. H.; Shaw, D. E.; Shelley, M.; Perry, J. K.; Francis, P.; Shenkin, P. S. J. Med. Chem. 2004, 47, 1739-1749.

14. The Cambridge Crystallographic Data Centre. URL (http://www.ccdc.cam.ac.uk/Solutions/GoldSuite/Pages/GOLD.aspx) (August 21, 2015).

15. McGann, M.; Almond, H.; Nicholls, A.; Grant, J. A.; Brown, F. Biopolymers 2003, 68, 76-90.

16. Dewar, M. J. S.; Zoebisch, E. G.; Healy, E. F.; Stewart, J. J. P. J. Am. Chem. Soc. 1985, 107, 3902-3909.

17. Stewart, J. J. P. 1989, 10, 209-220.

18. Mayeno, A. N.; Robinson, J. L.; Yang, R. S. H.; Reisfeld, B. J. Chem. Inf. Model. 2009, 49, 1692-1703.

19. Korzekwa, K. R.; Jones, J. P.; Gillettet, J. R. $\quad$ J. Am. Chem. Soc. 1990, 112, 7042-7046.

20. Sheridan, R. P.; Korzekwa, K. R.; Torres, R. A.; Walker, M. J. J. Med. Chem. 2007, 50, 3173-3184.

21. Rydberg, P.; Gloriam, D. E.; Zaretzki, J.; Breneman, C.; Olsen, L. ACSMed. Chem. Lett. 2010, $1,96-100$.

22. Groot, M. J. de; Ackland, M. J.; Horne, V. A.; Alex, A. A.; Jones, B. C. J. Med. Chem. 1999, $42,4062-4070$.

23. Oh, W. S.; Kim, D. N.; Jung, J.; Cho, K.-H.; No, K. T. J. Chem. Inf. Model. 2008, 48, 591-601.

24. Cruciani, G.; Carosati, E.; Boeck, B. De; Ethirajulu, K.; Mackie, C.; Howe, T.; Vianello, R. $\quad J$. Med. Chem. 2005, 48, 6970-6979.

25. Dong, D.; Wu, B.; Chow, D.; Hu, M. $\quad$ Drug Metab. Reviews 2012, 44, 192-208. 
26. Yasuda, K.; Ikushiro, S.; Kamakura, M.; Ohta, M.; Sakaki, T. Drug Metab. Dispos. 2010, 38, 2117-2123.

27. Nippon Soda Co., Ltd., Summary of pesticides, Tebfenozide. (insecticide) URL (http://www.acis.famic.go.jp/syouroku/tebfenozide/tebfenozide_01.pdf) (In Japanese, May 28, 2015).

28. Nakagawa, Y.; Shimizu, B.; Oikawa, N.; Akamatsu, M.; Nishimura, K.; Kurihara, N.; Ueno, T.;

Fujita, T. In Classical and Three-Dimensional QSAR in Agrochemistry; Hansch, C., Fujita, T., Eds.; American Chemical Society, Washington, DC, 1995, pp. 288-301.

29. Becke, A. D. J. Chem. Phys. 1993, 98, 1372-1377.

30. Becke, A. D. J. Chem. Phys. 1993, 98, 5648-5652.

31. Lee, C. T.; Yang, W. T.; Parr, R. G. Phys. Rev. B 1988, 37, 785-789. 


\section{Figure captions}

Fig. 1. Structure of tebufenozide

Fig. 2. Proposed MS fragmentation pathways for tebufenozide metabolites M1-M5

Fig. 3. Structures of tebufenozide metabolites with the production ratio by CYP3A4 and CYP2C19

Fig. 4. Examples of docking poses of tebufenozide to CYP3A4 (PDB ID: 3UA1) (A) and CYP2C19 (B). Active site shapes and tebufenozide are shown by blue lines and the orange color, respectively. The heme is located at the left side of each figure.

Fig. 5. The synthesis scheme of compounds with the M1 structure (racemic compound and $R$-enantiomer) and M2 structure 